\title{
Biphasic alterations of nociceptive thresholds induced by food deprivation
}

\author{
RICHARD J. BODNAR, DENNIS D. KELLY, ANGELA SPIAGGIA \\ and MURRAY GLUSMAN \\ Department of Behavioral Physiology, New York State Psychiatric Institute \\ and Department of Psychiatry, Columbia University, New York, New York 10032
}

\begin{abstract}
Acute exposure to such stressful events as inescapable footshock, rotation, or cold-water swims produces a transient analgesia. The physiological effects of food deprivation resemble those of an environmental stressor, in that corticosterone levels increase during food restriction and fall following meals. The present study investigated whether food deprivation, like other stressors, would produce a transient analgesia. Flinch-jump thresholds of 16 rats, maintained on a 14-h-light/10-h-dark cycle, were tested twice daily for 4 baseline, 3 food-deprivation, and 2 recovery days. Deprivation was initiated for eight animals at the beginning of the dark cycle (p.m. group), and for eight animals at the end of the dark cycle (a.m. group). Nociceptive thresholds of the p.m. group increased after $12 \mathrm{~h}$ of deprivation and decreased after 36 and $60 \mathrm{~h}$. Thresholds of the a.m. group were increased for up to $36 \mathrm{~h}$ of deprivation and decreased after $72 \mathrm{~h}$. Thresholds were higher after the dark cycle on the 1st deprivation day, and lower on the 3rd deprivation day, indicating an important circadian rhythmicity. Changes in weight, water intake, or activity levels could not account for the nociceptive alterations. These results provide further support for the contention that initial exposure to severe environmental stressful events produces a transient analgesia.
\end{abstract}

Stressful events produce a number of autonomic adjustments in the organism of varying degree and duration, such as changes in heart rate, muscle vasodilation, pupillary dilation, glucose and fat mobilization, constriction of capillary beds of the skin, and altered respiration, as well as a complex, but integrated, neuroendocrine response, involving activation of the pituitary-adrenocortical and sympathomedullary axes (Mason, 1968a, 1968b; Selye, 1952). Recent studies have demonstrated that another component of the emergency response to stress may be a reduction in sensitivity to painful stimuli. When rats were acutely exposed to repeated inescapable footshock, the latency to withdraw their tails from radiant head increased (Akil, Madden, Patrick, \& Barchas, 1976; Hayes, Bennett, Newlon, \& Mayer, 1976; Madden, Akil, Patrick, \& Barchas, 1977). In like fashion, acute exposure to other stressful events, such as cold-water swims, forced rotation, and intraperitoneal injections of hypertonic saline also produced analgesia lasting up to $2 \mathrm{~h}$ following the stressful event (Bodnar, Kelly, Spiaggia, \& Glusman, 1977; Hayes et al., 1976).

The authors wish to thank M. E. McManus and L. Skaredoff for technical assistance. R. J. B. was a postdoctoral fellow supported by NIMH Interdisciplinary Research Training Program Grant 13579. Research was also supported, in part, by Grant 365 from the New York State Health Research Council to D. D. K. Address all correspondence to: Dr. R. J. Bodnar, Department of Behavioral Physiology, New York State Psychiatric Institute, 722 West 168 Street, New York, New York 10032.
However, if the same animal is repeatedly exposed to the same stressful situation, the analgesic effects adapt (Akil et al., 1976; Bodnar et al., 1977; Madden et al., 1977). These data suggest that when extreme environmental demands are made upon an organism, a transient increase in nociceptive threshold results. To extend this hypothesis, the present study investigated whether abrupt food deprivation would also produce a transient analgesia in the starved animal. That food deprivation might qualify as a painmodulating stressful event is suggested by several observations. Normal feeding cycles, as well as imposed cycles of limited food availability, are correlated with orderly changes in steroid stress hormones (Coover, Goldman, \& Levine, 1971; Coover, Sutton, \& Heybach, 1977; Johnson \& Levine, 1973; Krieger, 1974; Levine \& Coover, 1976). Corticosterone levels increase during periods of food restriction and fall after meals (Coover et al., 1971; Krieger, 1974; Levine \& Coover, 1976). Acute, unexpected food deprivation also precipitates some behaviors which normally covary with pituitary-adrenal activation, such as shock-induced aggression and adjunctive or displacement behaviors (Falk, 1961; Kelly, 1974; Oatley \& Tonge, 1969; Panksepp, Toates, \& Oatley, 1972).

Previous studies investigating the effects of food deprivation upon nociception have reported mixed results. Dinsmoor (1958) limited animals daily to $2 \mathrm{~h}$ of access to food while training them to escape from suprathreshold footshock, and found no changes in 
escape responding following $24 \mathrm{~h}$ of food deprivation. However, Franchina (1966), using a similar design but lower shock levels, reported that deprived rats escaped more rapidly than normal. Misanin and Campbell (1969) found that up to 7 days of food deprivation in rats failed to alter either conditioned avoidance or psychophysical escape responding. Finally, two studies employing reflex withdrawal measures of nociception demonstrated that only 1 day of food deprivation was necessary to increase shock thresholds defined in terms of elicited vocalization, defecation, and urination, whereas flinch-jumpdefined thresholds were unaffected (Blanchard \& Blanchard, 1966; Griffiths, 1962).

In light of these mixed results, the present study was designed to maximize the stressful properties of the food-deprivation procedure. First, food deprivation occurred precipitously following a prior lifetime history of ad-lib feeding. Second, since rodent food consumption occurs primarily at night (Le Magnen \& Tallon, 1966), the stress-inducing potential of food deprivation should be maximal if the initial withdrawal of food occurs during the subject's dark cycle. The present study was specifically designed to test this possibility. Nociceptive threshold tests were conducted twice daily, at the beginning and end of a 10-h dark cycle. In one experimental group, food deprivation was initiated at the beginning of the dark cycle, and in the other at the end of the dark cycle.

\section{METHOD}

Sixteen male albino Holtzman Sprague-Dawley rats (300-600 g) were individually housed and maintained on a 14-h-light/10-h-dark cycle, in which lights went on at 0800 and off at 2200 daily. Initially, laboratory chow and water were available ad lib.

Flinch, initial jump, and jump thresholds were determined twice daily in 10-trial sessions using an ascending method of limits of successively more intense footshocks (Evans, 1961). Each animal was tested in an operant conditioning chamber $(26.5 \times 30 \times 24 \mathrm{~cm})$ with a grid floor composed of 14 grid bars $(0.6 \mathrm{~cm}$ diam $)$, spaced $1.8 \mathrm{~cm}$ apart. Electric shocks were delivered to the grids by a constant-current shock generator through a shock scrambler. The flinch threshold was defined in milliamps as the lowest intensity that elicited a withdrawal of a single paw from the grids. The initial jump threshold was defined as the lowest intensity that elicited simultaneous removal of both hind paws from the grids. The jump threshold was defined as the lowest of two consecutive intensities that elicited a jump, as above. Each trial began with the animal receiving a 300 -msec footshock at a current intensity of $0.1 \mathrm{~mA}$. Subsequent shocks were administered in equal $0.05-\mathrm{mA}$ increments at $10-\mathrm{sec}$ intervals. Following the determination of flinch, initial jump, and jump thresholds on each trial, the current intensity was reset to $0.1 \mathrm{~mA}$ for the next trial until 10 trials were completed.

Just prior to each test session, weight, food intake, water intake, and activity levels were measured, the latter by placing each animal's home cage for $5 \mathrm{~min}$ on an activity meter (Columbus Instruments) capable of counting both horizontal and vertical movements.

Two groups of eight animals each entered a 9-day experimental paradigm comprising 1 day of acclimation to the test procedures, 3 days of baseline testing, 3 days of food deprivation during which food, but not water, was removed from the home cage, and 2 days of recovery with food continuously available. The first test session of each day occurred between 0800 and $1000 \mathrm{~h}$ (a.m. session), at the beginning of every subject's light cycle, while the other occurred between 2000 and 2200 h (p.m. session), just prior to the end of the light cycle.

In one group of eight rats (p.m. group), food was removed immediately following a baseline p.m. session, that is, at the beginning of a dark cycle when rats are most likely to eat; hence the initial food-deprivation test occurred during an a.m. session. Consequently, for the p.m. group, the a.m. flinch-jump test sessions occurred after 12,36 , and $60 \mathrm{~h}$ of deprivation, while the p.m. test sessions occuried after 24,48 , and $72 \mathrm{~h}$ of deprivation. In the second group of eight rats (a.m. group), food was removed immediately following a baseline a.m. session, that is, early in a light cycle when rats are less likely to eat; hence, the initial food-deprivation test occurred during a p.m. session. Consequently, for the a.m. group, the p.m. flinch-jump test sessions occurred after 12,36 , and $60 \mathrm{~h}$ of deprivation, while the a.m. test sessions occurred after 24,48 , and $72 \mathrm{~h}$ of deprivation.

\section{RESULTS}

Figure 1 summarizes the effects of the various experimental manipulations upon jump thresholds across conditions and groups. Initial jump thresholds displayed a similar pattern of effects; however, flinch thresholds did not always mirror the two jump measures. It is not uncommon for flinch and jump thresholds to be dissociated in this manner (Evans, 1961; Mayer \& Liebeskind, 1974). As predicted, the initial consequence of food deprivation in both groups was an increase in jump thresholds. As deprivation continued, thresholds eventually returned to normal levels. Reintroduction of food normalized jump thresholds during the recovery stage.

Significant changes in each separate nociceptive measure were determined by a two-way analysis of

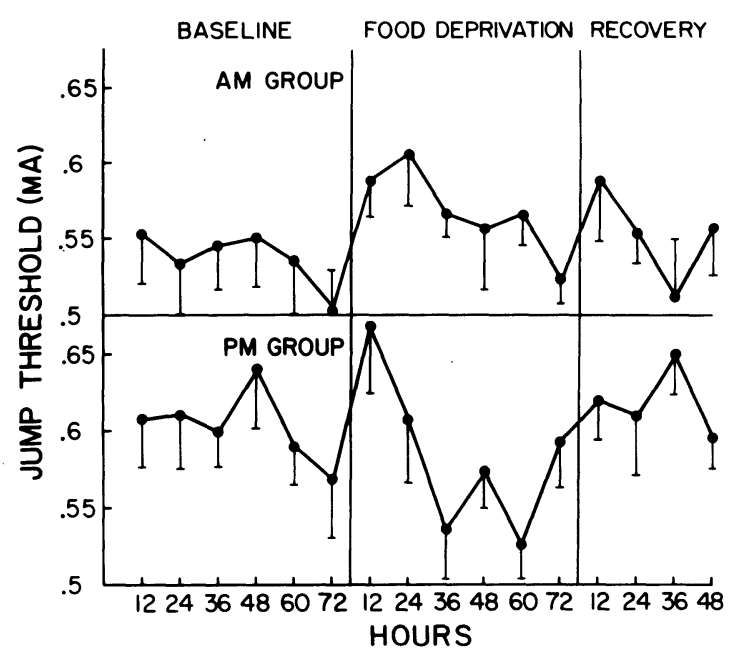

Figure 1. Alterations in mean jump thresholds ( \pm S.E.M.) during baseline, food deprivation, and recovery conditions. Food was removed at the end of the dark cycle for the a.m. group $(n=8)$, and at the end of the light cycle for the p.m. group $(\mathbf{n}=\mathbf{8})$. 
Table 1

The Effects of 72-h Food Deprivation (Relative to Prior Baseline) Upon Three Nociceptive Response Measures in Rats

\begin{tabular}{|c|c|c|c|c|c|c|c|c|c|c|c|c|}
\hline \multirow[b]{2}{*}{ Group } & & \multirow[b]{2}{*}{ Baseline } & \multicolumn{6}{|c|}{ Food Deprivation } & \multicolumn{4}{|c|}{ Recovery } \\
\hline & & & 12 & 24 & 36 & 48 & 60 & 72 & 12 & 24 & 36 & 48 \\
\hline \multicolumn{13}{|c|}{ Jump Thresholds } \\
\hline $\mathrm{AM}$ & $\begin{array}{l}\text { Mean } \\
\mathrm{t} \\
\mathrm{p}<\end{array}$ & .536 & $\begin{array}{c}.588 \\
3.05 \\
.02\end{array}$ & $\begin{array}{c}.606 \\
4.45 \\
.01\end{array}$ & $\begin{array}{c}.567 \\
2.19 \\
*\end{array}$ & $\begin{array}{l}.555 \\
.86 \\
*\end{array}$ & $\begin{array}{c}.565 \\
1.89 \\
*\end{array}$ & $\begin{array}{c}.522 \\
1.86 \\
*\end{array}$ & $\begin{array}{c}.589 \\
1.92 \\
*\end{array}$ & $\begin{array}{l}.553 \\
.63 \\
*\end{array}$ & $\begin{array}{c}.511 \\
1.16 \\
*\end{array}$ & $\begin{array}{c}.557 \\
1.62 \\
*\end{array}$ \\
\hline PM & $\begin{array}{l}\text { Mean } \\
\mathrm{t} \\
\mathrm{p}<\end{array}$ & .604 & $\begin{array}{c}.666 \\
3.11 \\
.02\end{array}$ & $\begin{array}{l}.606 \\
.004 \\
*\end{array}$ & $\begin{array}{c}.533 \\
5.25 \\
.001\end{array}$ & $\begin{array}{c}.572 \\
1.09 \\
*\end{array}$ & $\begin{array}{c}.525 \\
5.01 \\
.01\end{array}$ & $\begin{array}{l}.591 \\
.73 \\
*\end{array}$ & $\begin{array}{l}.619 \\
.67 \\
*\end{array}$ & $\begin{array}{l}.609 \\
.93 \\
*\end{array}$ & $\begin{array}{c}.649 \\
2.88 \\
.05\end{array}$ & $\begin{array}{l}.594 \\
.48 \\
*\end{array}$ \\
\hline \multicolumn{13}{|c|}{ Initial Jump Thresholds } \\
\hline $\mathrm{AM}$ & $\begin{array}{l}\text { Mean } \\
\mathrm{t} \\
\mathrm{p}<\end{array}$ & .505 & $\begin{array}{c}.522 \\
2.32 \\
.05\end{array}$ & $\begin{array}{l}.514 \\
.92 \\
*\end{array}$ & $\begin{array}{l}.501 \\
.16 \\
*\end{array}$ & $\begin{array}{l}.499 \\
.27 \\
*\end{array}$ & $\begin{array}{l}.516 \\
.54 \\
*\end{array}$ & $\begin{array}{c}.446 \\
2.85 \\
.05\end{array}$ & $\begin{array}{c}.534 \\
1.51 \\
*\end{array}$ & $\begin{array}{l}.499 \\
.06 \\
*\end{array}$ & $\begin{array}{c}.451 \\
3.31 \\
.02\end{array}$ & $\begin{array}{l}.499 \\
.12 \\
*\end{array}$ \\
\hline PM & $\begin{array}{l}\text { Mean } \\
\mathrm{t} \\
\mathrm{p}<\end{array}$ & .542 & $\begin{array}{c}.576 \\
4.59 \\
.01\end{array}$ & $\begin{array}{c}.546 \\
1.46 \\
*\end{array}$ & $\begin{array}{c}.490 \\
5.91 \\
.001\end{array}$ & $\begin{array}{l}.523 \\
.70 \\
*\end{array}$ & $\begin{array}{c}.472 \\
6.41 \\
.001\end{array}$ & $\begin{array}{l}.531 \\
.39 \\
*\end{array}$ & $\begin{array}{c}.582 \\
1.84 \\
*\end{array}$ & $\begin{array}{c}.568 \\
1.08 \\
*\end{array}$ & $\begin{array}{c}.599 \\
2.34 \\
.05\end{array}$ & $\begin{array}{l}.543 \\
.04 \\
*\end{array}$ \\
\hline \multicolumn{13}{|c|}{ Flinch Thresholds } \\
\hline $\mathrm{AM}$ & $\begin{array}{l}\text { Mean } \\
\mathrm{t} \\
\mathrm{p}<\end{array}$ & .216 & $\begin{array}{c}.231 \\
1.34 \\
*\end{array}$ & $\begin{array}{c}.196 \\
1.42 \\
*\end{array}$ & $\begin{array}{l}.213 \\
.14 \\
*\end{array}$ & $\begin{array}{l}.222 \\
.56 \\
*\end{array}$ & $\begin{array}{l}.226 \\
.75 \\
*\end{array}$ & $\begin{array}{c}.196 \\
1.56 \\
*\end{array}$ & $\begin{array}{c}.241 \\
1.41 \\
*\end{array}$ & $\begin{array}{l}.211 \\
.24 \\
*\end{array}$ & $\begin{array}{c}.191 \\
2.71 \\
.05\end{array}$ & $\begin{array}{l}.191 \\
2.19 \\
*\end{array}$ \\
\hline PM & $\begin{array}{l}\text { Mean } \\
\mathrm{t} \\
\mathrm{p}<\end{array}$ & .232 & $\begin{array}{c}.216 \\
1.59 \\
*\end{array}$ & $\begin{array}{c}.256 \\
2.37 \\
.05 \\
\end{array}$ & $\begin{array}{c}.204 \\
2.83 \\
.05 \\
\end{array}$ & $\begin{array}{c}.202 \\
1.53 \\
*\end{array}$ & $\begin{array}{c}.189 \\
4.61 \\
.01 \\
\end{array}$ & $\begin{array}{r}.187 \\
2.71 \\
.05 \\
\end{array}$ & $\begin{array}{l}.223 \\
.06 \\
*\end{array}$ & $\begin{array}{c}.257 \\
1.82 \\
*\end{array}$ & $\begin{array}{c}.204 \\
2.47 \\
.05 \\
\end{array}$ & $\begin{array}{c}.213 \\
2.34 \\
.05 \\
\end{array}$ \\
\hline
\end{tabular}

*Nonsignificant.

variance, which included the a.m. and p.m. groups as one main effect, and compared differences between baseline, food deprivation, and recovery conditions for the second main effect. While the a.m. and p.m. groups did not differ from one another for any nociceptive measure except jump thresholds $[\mathrm{F}(1,174)$ $=9.78, \mathrm{p}<.01]$, there were significant differences among the baseline, food deprivation, and recovery conditions for all three measures: jump $[F(15,224)$ $=2.77, \mathrm{p}<.01]$, initial jump $[\mathrm{F}(15,224)=2.31$, $\mathrm{p}<.01]$, and flinch $[\mathrm{F}(15,224)=2.40, \mathrm{p}<.01]$. A posteriori Tukey comparisons were made between the baseline condition and each of the food-deprivation and recovery conditions. Since significant differences were found between the a.m. and p.m. groups for jump thresholds, each group was analyzed separately.

Table 1 statistically summarizes the effects of food deprivation upon all threshold measures for both groups. In the a.m. group, initial jump and jump thresholds significantly increased following $12 \mathrm{~h}$ of food deprivation. Jump thresholds remained elevated after 24 and $36 \mathrm{~h}$ of deprivation. However, by $72 \mathrm{~h}$ of deprivation, initial jump thresholds were significantly lower than baseline levels, while jump thresholds, though also lower than normal, were not significantly so. Most recovery values were within normal limits except for a significant decline in initial jump, but not jump thresholds, after $36 \mathrm{~h}$ of renewed feeding.

In the p.m. group, initial jump and jump thresholds also significantly increased following $12 \mathrm{~h}$ of food deprivation, but, unlike the a.m. group, they had returned to normal by $24 \mathrm{~h}$ of deprivation. In fact, significant hypersensitivity in both jump measures occurred at both 36 and $60 \mathrm{~h}$ of deprivation. Most recovery values were again within normal limits, except for a significant increase instead of a decrease, as in the a.m. group, in both jump measures after $36 \mathrm{~h}$ of food availability. Thus, in general, the biphasic threshold changes induced by starvation and initial elevation followed by a decline, were similar in a.m. and p.m. groups, with the cycles of the latter group more compact and severe. Finally, while nociceptive thresholds did not differ between a.m. and p.m. sessions during baseline and recovery, jump thresholds were significantly higher $[\mathrm{t}(15=2.25$, $p<.05]$ during the a.m. session on the 1 st day of deprivation, while both initial jump $[\mathrm{t}(15)=3.56$, $\mathrm{p}<.01]$ and jump $[\mathrm{t}(15)=4.14, \mathrm{p}<.001]$ measures were significantly lower during the a.m. session by the 3rd deprivation day.

Figure 2 shows that though the a.m. and p.m. groups differed from one another in body weight $[F(1,224)=90.1, \quad p<.01], \quad$ significant weight loss $[F(15,224)=4.06, p<.01]$ was observed for both groups to $87 \%$ of baseline during food deprivation. Body weights returned to $94 \%$ of baseline after 2 days of resumed feeding. Water intake significantly decreased $[\mathrm{F}(15,224)]=6.95, \mathrm{p}<.01]$ during deprivation $(31 \mathrm{ml})$, with a return to baseline levels $(55 \mathrm{ml})$ during recovery $(59 \mathrm{ml})$. Water intake was always significantly higher $[\mathrm{t}(15)=20.68$, 


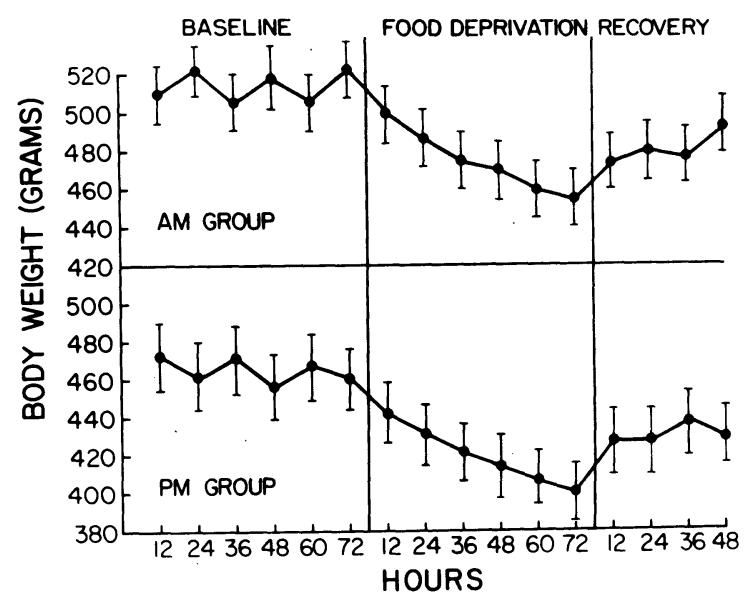

Figure 2. Alterations in weight $( \pm$ S.E.M.) during baseline, food deprivation, and recovery conditions.

$\mathrm{p}<.001$ ] during the dark cycle $(33.2 \mathrm{ml})$ than during the light cycle $(9.2 \mathrm{ml})$. Food intake also was significantly higher during the dark cycle $(24.7 \mathrm{~g})$ than during the light cycle $(13.4 \mathrm{~g})$ for both baseline $[\mathrm{t}(15)=25.60, \mathrm{p}<.001]$ and recovery $[\mathrm{t}(15)=10.19$, $\mathrm{p}<.001]$ conditions.

Figure 3 shows the alterations in activity levels for both groups across the baseline, food-deprivation, and recovery conditions. Again, there were significant differences between the a.m. and p.m. groups in gross activity levels $[\mathrm{F}(1,224)=18.3, \mathrm{p}<.01]$ and also between the baseline, food-deprivation, and recovery conditions $[F(10,165)=1.91, p<.05]$. Activity was significantly higher during the a.m. session throughout baseline $[\mathrm{t}(95)=2.49, \mathrm{p}<.02]$ and the first deprivation day $[\mathrm{t}(15)=2.44, \mathrm{p}<.05]$. Regardless of the momentary direction of nociceptive threshold shifts during food deprivation, concurrent activity level measures for the two groups showed no parallel changes; in fact, they showed no significant differences from their respective baselines.

\section{DISCUSSION}

The principal finding of the present experiment is that abrupt food deprivation results in a temporally biphasic alteration in pain thresholds. Jump thresholds were significantly elevated during the initial hours of deprivation, with the exact time course of this initial analgesia dependent upon when the deprivation was initiated relative to the subjects' light-dark cycle. By the 3rd day, thresholds became more sensitive than normal in all animals.

These nociceptive alterations were clearly not incidental to changes in body weight and/or general activity levels. Since body weight decreased uniformly throughout deprivation, it cannot be said to account for the biphasic time course of pain sensitivity.
Moreover, identical weight loss to $94 \%$ of deprivation occurred both following $12 \mathrm{~h}$ of deprivation, when animals displayed analgesia, and following $48 \mathrm{~h}$ of recovery, when normal nociceptive thresholds were observed. Activity levels similarly failed to predict the time-course of nociceptive alterations. Although water intake decreased during deprivation, consumption was uniform over the 3 days of deprivation. Circadian patterns of drinking were unchanged.

The initial elevation of thresholds caused by food deprivation corresponds with other reports that showed similar elevations in thresholds necessary to elicit vocalization, urination, and defecation (Blanchard \& Blanchard, 1966; Griffiths, 1962). However, in some studies, food deprivation has been found to be without apparent effect upon flinchjump thresholds (Blanchard \& Blanchard, 1966), operant escape, or avoidance schedules maintained by electric shock (Dinsmoor, 1958; Misanin \& Campbell, 1969). Several procedural differences between these and the present study are apparent. First, in the present study, food was withdrawn precipitously rather than gradually. Second, operant escape schedules require that much longer trains of grid shock be delivered at clearly suprathreshold intensities to maintain escape responding, and thus may not be comparable to psychophysical procedures employing marginally aversive stimuli, nor may they be as sensitive. Third, the behavioral sessions may have been carried out at different times in the subjects' circadian cycles, for the latter were not reported in these studies.

The circadian alterations in nociceptive thresholds during food deprivation provided empirical support for the contention that initial exposure to food deprivation, acting as a stressful event, should transiently increase pain thresholds. Since rodent food consumption is most prevalent during the animal's

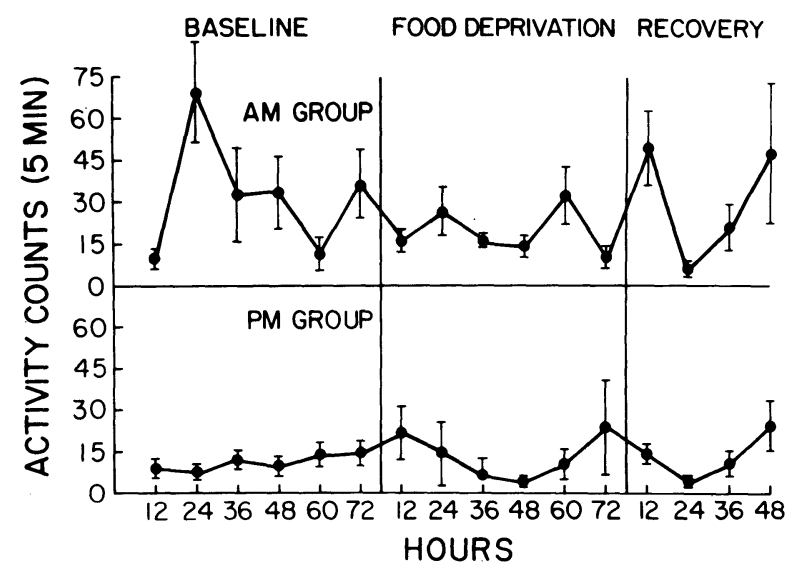

Figure 3. Alterations in activity ( \pm S.E.M.) throughout the experiment. Activity was measured as the cumulated number of horizontal and vertical movements over $5 \mathrm{~min}$. 
dark cycle (Le Magnen \& Tallon, 1966), deprivation commencing at the end of an animal's light cycle should increase nociceptive thresholds most rapidly. The p.m. group, deprived in this manner, confirmed this hypothesis in that both jump measures were elevated after $12 \mathrm{~h}$ of deprivation. In contrast, deprivation commencing at the end of an animal's dark cycle should result in more delayed and perhaps prolonged analgesia, with the maximal effect occurring 24, rather that $12 \mathrm{~h}$ after deprivation. The a.m. group, deprived in this manner, confirmed this hypothesis by displaying analgesia which lasted $36 \mathrm{~h}$ and produced its peak effects after $24 \mathrm{~h}$ of deprivation. Also, during this initial period of deprivationinduced analgesia, significantly higher nociceptive thresholds occurred at the end of the dark, rather than at the end of the light period. This indicates that nociceptive alterations during food deprivation are most profound when food is normally expected. Deprivation-induced threshold elevations dissipated rather quickly, by $24 \mathrm{~h}$ of deprivation for the p.m. group, and $48 \mathrm{~h}$ for the a.m. group. This pattern seems to mimic the transient nature of analgesia induced by acute exposure to other stressful events (Akil et al., 1976; Bodnar et al., 1977; Hayes et al., 1976; Madden et al., 1977). Moreover, these results seem to extend the phenomenon of stress-produced analgesia, since the food-deprivation procedure, though stressful as measured by steroid stress hormones (Coover et al., 1971, 1977; Johnson \& Levine, 1973; Krieger, 1974; Levine \& Coover, 1976), is not painful. This is important, since most other stressful events which produce analgesia, such as inescapable footshock, cold-water swims, rotation, and injections of hypertonic saline are also painful events in and of themselves. Overall, the present study lends further support to the contention that initial exposure to severe environmental demands, which appear to activate underlying stress-response mechanisms, produces a transient analgesia.

\section{REFERENCES}

Akil, F., Madden, J., Patrick, R. L., \& Barchas, J. D. Stress-induced increase in endogenous opiate peptides: Concurrent analgesia and its partial reversal by naloxone. In Opiates and endogenous opiate peptides. Amsterdam: North Holland, 1976. Pp. 63-70.

Blanchard, R. T., \& Blanchard, D. C. Food deprivation and reactivity to shock. Psychonomic Science, 1966, 4, 317-318.

Bodnar, R. J., Kelly, D. D., Spiaggia, A., \& Glusman, M. Analgesia produced by cold-water stress: Effect of naloxone. Federation Proceedings, 1977, 36.
Coover, G. D., Goldman, L., \& Levine, S. Plasma corticosterone increases produced by extinction of operant behavior in rats. Physiology \& Behavior, 1971, 6, 216-263.

Coover, G. D., Sutton, B. R., \& Heybach, J. P. Conditioned decreases in plasma corticosterone level in rats by pairing stimuli with daily feedings. Journal of Comparative and Physiological Psychology, 1977, 91, 716-726.

Dinsmoor, J. A. Pulse duration and food deprivation in escapefrom-shock training. Psychological Reports, 1958, 4, 531-534.

Evans, W. O. A new technique for the investigation of some analgesic drugs on a reflexive behavior in the rat. Psychopharmacologia, 1961, 2, 318-325.

FALK, J. Production of polydipsia in normal rats by an intermittent food schedule. Science, 1961, 133, 195-196.

Franchina, J. J. Combined sources of motivation and escape responding. Psychonomic Science, 1966, 6, 221-222.

GRIFFITHS, W. J. Effect of food and water deprivation on shock tolerance of albino rats. Psychological Reports, 1962, 11, 163-166.

Hayes, R. L., Bennett, G. J., Newlon, P., \& Mayer, D. J. Analgesic effects of certain noxious and stressful manipulations in the rat. Society for Neuroscience Abstracts, 1976, 2, No. 1350.

JoHnsox, J. T., \& LEvine, S. Influence of water deprivation on adrenocortical rhythms. Neuroendocrinology, 1973, 11, 268-273.

Kelly, D. D. The experimental imperative: Laboratory analyses of aggressive behaviors. In Aggression Research Publications A.R.N.M.D. (Vol. 52), 1974.

KRIRGRR, D. T. Food and water restriction shifts corticosterone, temperature, activity and brain amine periodicity. Endocrinology, 1974, 95, 1195-1201.

Le Magnen, J., \& Tallon, S. La periodicité spontanée de la prise d'aliments ad libitum du rat blanc. Journal of Physiology (Paris), 1966, 58, 323-349.

Levine, S., \& Coover, G. D. Environmental control of suppression of the pituitary-adrenal system. Physiology \& Behavior, 1976, 17, 35-37.

Madden, J., Akil, H., Patrick, R. L., \& Barchas, J. D. Stressinduced parallel changes in central opioid levels and pain responsiveness in the rat. Nature, 1977, 265, 358-360.

Mason, J. W. A review of psychoendocrine research on the pituitary-adrenal cortical system. Psychosomatic Medicine, 1968, 30, 576-607. (a)

Mason, J. W. A review of psychoendocrine research on the sympathetic adrenal medullary system. Psychosomatic Medicine, 1968, 30, 631-633. (b)

MAYeR, D. J., \& Liebeskind, J. C. Pain reduction by focal electrical stimulation of the brain: An anatomical and behavioral analysis. Brain Research, 1974, 68, 73-93.

Misanin, J. R., \& CAmpbell, B. A. Effects of hunger and thirst on sensitivity and reactivity to shock. Journal of Comparative and Physiological Psychology, 1969, 69, 207-213.

OATLEY, K., \& TONGE, D. A. The effect of hunger on water intake in rats. Quarterly Journal of Experimental Psychology, 1969, 21, 169.

Panksepp, J., Toates, F. M., \& Oatley, K. Extinction-induced drinking in hungry rats. Animal Behaviour, 1972, 20, 493.

SELYE, H. The story of the adaptation syndrome. Montreal: Acta, 1952.

(Received for publication December 21, 1977; revision accepted March 14, 1978.) 